$\overline{\text { 原 } \quad \text { 著 }}$

\title{
内頸動脈硬膜輪近傍動脈瘤の分類
}

$\begin{array}{llrl}\text { 京島 和彦, 及川 } & \text { 奏, 小池 譫治 } \\ \text { 外間 政信, 鳥山 } \text { 俊英, 宜保 浩彦 } \\ \text { 大沢 道彦, 重田 裕明, 中川 福夫 } \\ \text { 小林 茂昭 }\end{array}$

\section{A Classification of Juxta-dural Ring Aneurysms of Internal Carotid Artery}

Kazuhiko Kyoshima, M.D., Susumu Oikawa, M.D., George Korke, M.D.,

Masanobu Hokama, M.D., Toshihide ToriYama, M.D., Hirohiko GiBo, M.D.,

Mitihiko Osawa, M.D., Hiroaki Shigeta, M.D., Fukuo NaKagaWA, M.D., and

Shigeaki KOBAYASHI, M.D.

Department of Neurosurgery, Shinshu University School of Medicine, Matsumoto, Japan

Summary: We report a classification of juxta-dural ring aneurysms of the internal carotid artery (ICA). These aneurysms are classified into three types according to their relation to the carotid dural ring and the long axis of the ICA: paraclinoid intradural, carotid cave and infraclinoid extradural aneurysms. Another set of classification is made according to their location in relation to the cross section of the ICA as lateral, medial, ventral or dorsal type.

The paraclinoid intradural aneurysms arise from the ICA distal to the origin of the ophthalmic artery and are close to the dural ring, which may include some of so-called carotid-ophthalmic aneurysms. The carotid cave aneurysms are located intradurally in the carotid cave, a dural recess in the infraclinoid carotid groove, and proximal to the origin of the ophthalmic artery. They are located at the angiographical genu angiographically and in the intradural space anatomically. The infraclinoid extradural aneurysms are located extradurally in the infraclinoid segment close to the dural ring.

The infraclinoid extradural aneurysms should be differentiated from aneurysms in the cavernous sinus, because they are located in the infraclinoid carotid groove sinus, which is a peripheral venous space to the cavernous sinus.

Clipping of these aneurysms requires essentially the same surgical techniques: removal of the anterior clinoid process, unroofing of the optic canal, opening of the dural ring and exposure of the infraclinoid segment including the surgical genu and axilla of the ICA via the ipsilateral pterional approach.
Key words:

- internal carotid artery

- classification

- juxta-dural ring aneurysm

- surgical anatomy

- dural ring

Surg Cereb Stroke (Jpn) 25: 370-377, 1997

信州大学 脳神経外科(受稿日 1996.12.2)〔連絡先： T390 松本市旭3-1-1 信州大学医学部 脳神経外科 京島和彦] [Mailing address: Kazuhiko Kyoshima, M.D., Department of Neurosurgery, Shinshu University School of Medicine, 3-1-1 Asahi, Matsumoto 390, Japan] 

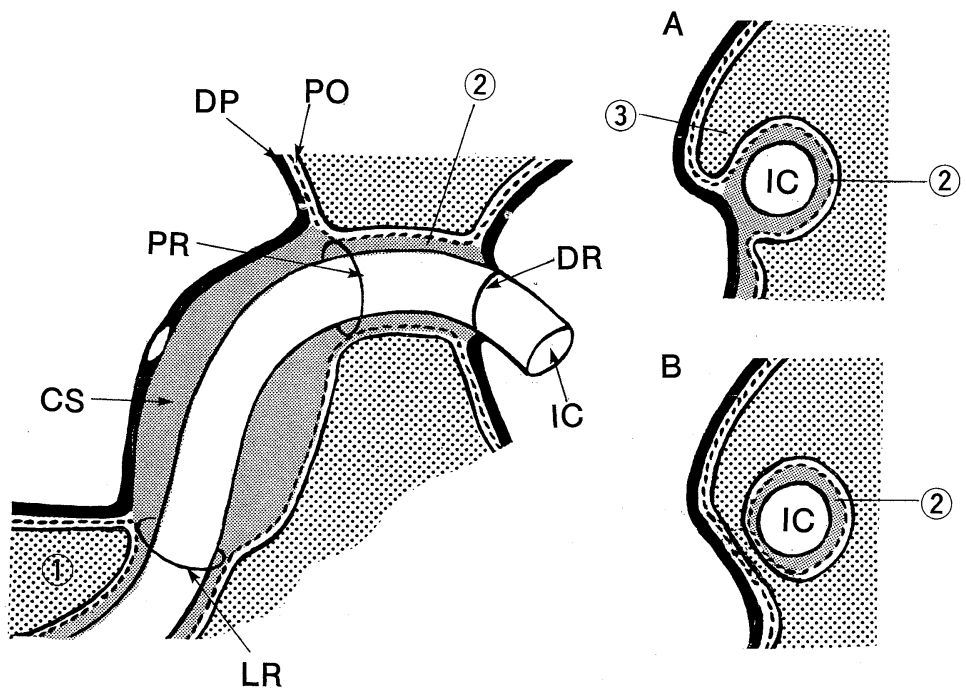

Fig. 1 Schematic drawing of the membranous structures along the internal carotid artery.

A: Sagittal section of the infraclinoid carotid groove. Note that the infraclinoid sinus (2) is covered with periosteum at the bony side (infraclinoid groove) and other side is covered with the dura propria.

B: Sagittal section of the caroticoclinoid foramen. Note that the infraclinoid sinus is covered with the periosteum.

CS: cavernous sinus, DR: dural ring (distal ring), DP: dura propria, IC: internal carotid artery, LR: lateral ring, PO: periosteum, PR: proximal ring. 1: bone of the temporal base, 2: infraclinoid sinus (infraclinoid carotid groove sinus), 3: anterior clinoid process. (文献10,12より一部改変)

はじめに

内頸動脈硬膜輪近傍に発生する動脈瘤については, 内頸 動脈硬膜輪近傍動脈瘤 juxta-dural ring aneurysmとしてす でに報告したが810)11)，硬膜輪近傍に発生する動脈瘤につ いては, 分岐動脈との関連, 眼動脈, 前床突起などの周囲 組織との関連, 血管写の所見などから, ventral internal carotid, paraclinoid, infraclinoidal, superior hypophyseal aneurysm 25)14)15)16)20)などとよばれ, dural ring, carotid cave, 海綿静脈洞など硬膜輪近傍の解剖学的解釈の相違か ら，種々の混乱を生じている ${ }^{8)}$.

これらの点をふまえて, 硬膜輪近傍の解剖, 分類の用語 上の問題なども含めて, 硬膜輪近傍動脈瘤の分類に対する 我々の考えを述べる。

\section{内頸動脈硬膜輪近傍の外科解剖 ${ }^{10) 12)}$}

内頸動脈は頭蓋外から骨膜に被われた carotid canal内を 通り頭蓋内に入る。中頭蓋底では固有硬膜 (dura propria) と骨膜 (periosteum) との間(海綿静脈洞)を走り，前床突起 基部を通過したところで固有硬膜を貫通し，硬膜内に入る (Fig. 1). この固有硬膜貫通部が内頸動脈硬膜輪 (carotid dural ring, dural ring, distal ring) ${ }^{3) 15)}$ である.
内頸動脈が破裂孔を出て，固有硬膜を貫通するまでの間 に形成される中頭蓋底(蝶形骨)の骨陥凹部は carotid grooveとよばれているが，特に前床突起基部の骨陷凹部 をinfraclinoid carotid groove (infraclinoid groove)とよぶ ことにすると, infraclinoid grooveは骨膜に覆われている が，骨組織のない部分では固有硬膜に覆われていることに なる(Fig. 1A). infraclinoid grooveは時に全周が骨に囲ま れていることがあり， caroticoclinoid foramenとよばれて いる。この場合は全周骨膜に覆われることになる (Fig. 1B).

infraclinoid groove内での内頸動脈周囲の venous space をinfraclinoid carotid groove sinus (infraclinoid sinus) と すると, infraclinoid sinusは真の海綿静脈洞ではなく, intercavernous sinusやbasilar sinusなどと同じ海綿静脈 洞周囲の venous spaceということになる。海綿静脈洞は 固有硬膜と骨膜に覆われた大きなvenous spaceといえる。 infraclinoid sinusの入り口が proximal ring ${ }^{3)}$ となる。 proximal ring を形成するものは骨に接する部分は骨膜で, 骨のない部分は固有硬膜である. proximal ringはdural ringのように内頸動脈とは直接癒合しておらず，内頸動脈 周囲には cavernous sinusと交通する spaceが存在するこ とになる。またinfraclinoid sinusは必ずしも開存している 


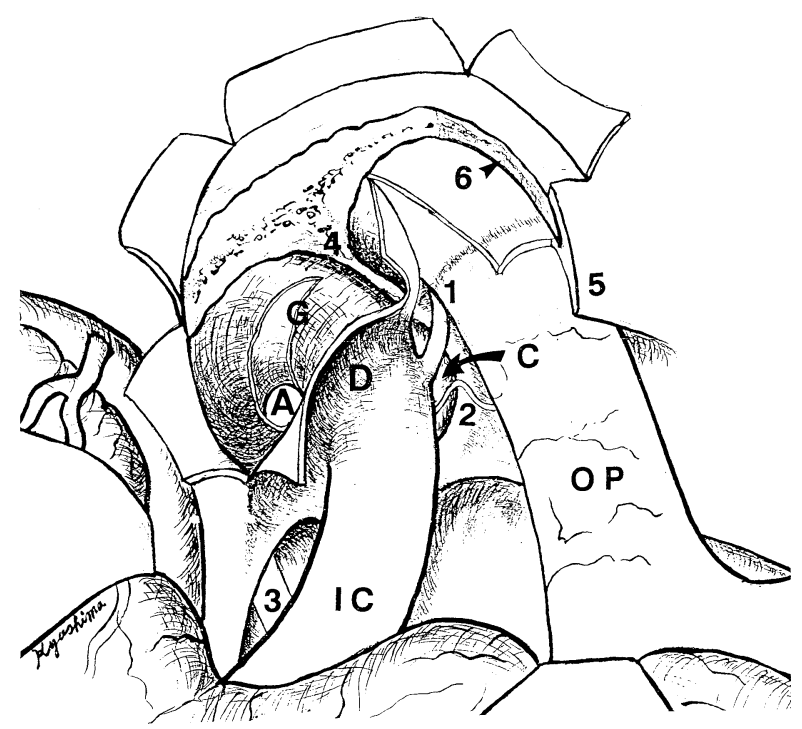

Fig. 2 Schematic drawing of surgical anatomy in the operative field after removal of the anterior clinoid process and optic roof (via left pterional approach rotating the head to the opposite side about 45 degrees).

Note that the internal carotid artery (ICA) penetrates the dural ring obliquely, the carotid cave is located ventrally where the superior hypophyseal artery originates from the ICA. The infraclinoid segment of ICA is partially exposed by dissecting the periosteum. The ICA of this area is running horizontally, and the dural ring adheres to the ICA tightly in the dorsal to lateral side.

A: axilla of ICA, C: carotid cave, D: dural ring, G: surgical genu of ICA, OP: optic nerve, IC: internal carotid artery. 1: ophthalmic artery, 2: superior hypophyseal artery, 3: oculomotor nerve, 4: optic strut, 5: falciform fold, 6: optic roof. (文献 10, 11, 12, 13 より引用）

わけではなく，部分的あるいは完全に閉鎖腔になっている こともある．完全な閉鎖腔になっている場合， proximal ring はdural ring と同様に内頸動脈に瘉合したringとして 認められる。 infraclinoid sinusは proximal ringと dural ringに境された, infraclinoid grooveという骨と骨のない 部分は固有硬膜とで囲まれた管状のvenous space という ことになる。したがって proximal ringを境に海綿静脈洞 とinfraclinoid sinus とは解剖学的に厳密に区別される.

infraclinoid groove 形成する前床突起を切除して認め られる硬膜外部分が clinoid space (我々はinfraclinoid spaceとよぶ $\left.{ }^{11)}{ }^{12}\right)$ であり, infraclinoid space内の venous spaceがinfraclinoid sinusということになる. infraclinoid space (正確にはinfraclinoid sinus内)を走る内頸動脈の部 分がclinoid segment (infraclinoid carotid groove segment, infraclinoid segment)である.

dural ringの一部は，時にinfraclinoid groove内にあり

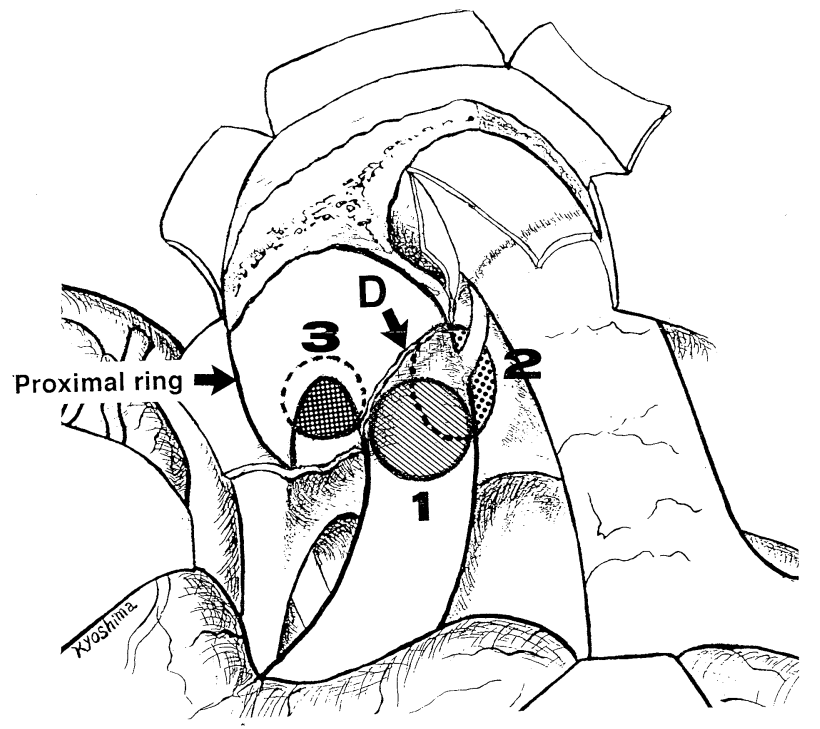

Fig. 3 Classification according to the long axis and anatomical relationship of the juxta-dural ring aneurysms via left pterional approach. 1: paraclinoid intradural aneurysm, 2: carotid cave aneurysm, 3: infraclinoid extradural aneurysm, D: dural ring. (文献10,11上 り引用）

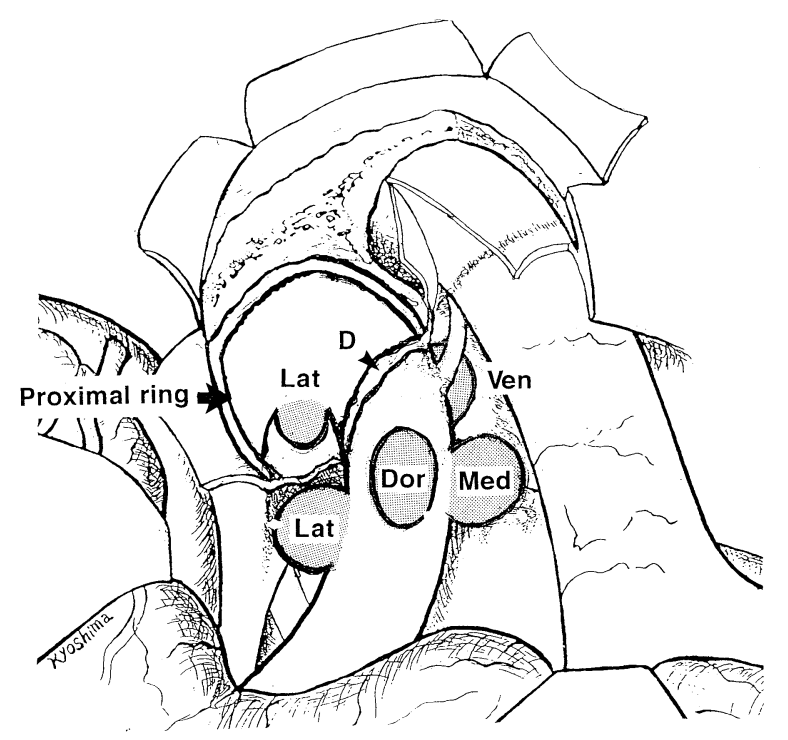

Fig. 4 Classification of the juxta-dural ring aneurysms according to the cross section. Lat: lateral aneurysm, Med: medial aneurysm, Ven: ventral aneurysm, Dor: dorsal aneurysm. D: dural ring

硬膜陥凹部を形成している。この硬膜陥凹部が carotid cave ${ }^{7) 9)}$ である。重要な点は, carotid caveは常に存在する 構造物ではないということである。

Fig. 2 は頭部を対側に約 45 度回転させた左 pterional approachで前床突起を切除し，視神経管を開放した実際 の術野に即した外科解剖の模式困である。硬膜輪近傍の解 

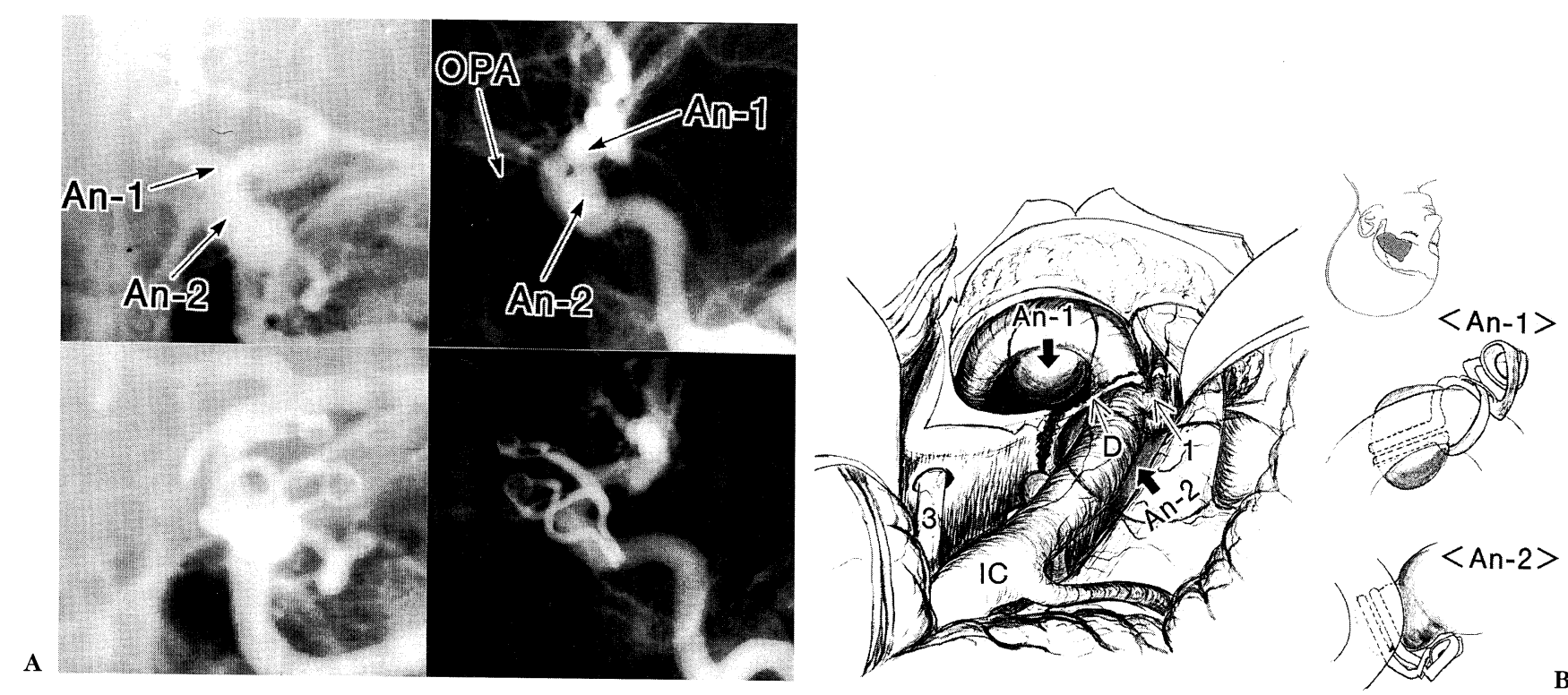

Fig. 5 Paraclinoid intradural aneurysm and infraclinoid extradural aneurysm (left).

A: Upper: Preoperative angiograms. A paraclinoid intradural aneurysm (An-1) protrudes medially on the A-P view, and protrudes posteriorly locating distally to the ophthalmic artery on the lateral view. An infraclinoid extradural aneurysm (An-2) is located just proximally to the angiographical genu on the lateral view. Lower: Postoperative angiograms. Note that the site of the aneurysms are precisely confirmed by the position of the clip blades. OPA: ophthalmic artery.

B: Operative drawing. The paraclinoid intradural aneurysm is situated ventrally locating just distally to the carotid dural ring in the operative field. The infraclinoid extradural aneurysm is situated laterally locating extradurally at the axilla (surgical genu) in the operative field. Abbreviations as in Fig. 2. (文献12より引用)

剖学的関係は前床突起を切除することにより露出される. infraclinoid groove と optic canalの骨性隔壁がoptic strut である.内頸動脈を硬膜内より硬膜外にたどると，内頸動 脈は外側に孤を描きながら内頸動脈の長軸に対して斜めに 固有硬膜を貫通している。このことから carotid caveの部 分は硬膜内であるが, 内頸動脈の長軸に対して反対側は硬 膜外(infraclinoid sinus) となる。骨膜を切開しinfraclinoid sinus を開放すると内頸動脈の infraclinoid segmentが露出 される。術野でinfraclinoid segmentの弯曲が最も強い部 分を外科的内頸動脈膝部(surgical genu)といい, さらにこ の弯曲部の内側が内頸動脈腋窩部(axilla)である。実際の 手術では, axillaに近い proximal ring 部で海綿静脈洞から の出血が特に多くみられる.

\section{内頸動脈硬膜輪近傍動脈瘤の分類}

我々の分類は, 前述の解剖学的位置関係を考慮した, 頭 部を対側に回転させたpterional approachでの術野におけ る分類であり, 分岐血管に関係なく, dural ringとの関係 において分類を行ったものである.すなわち, 内頸動脈の 長軸方向における動脈瘤の発生部位により, dural ring よ
り遠位側の硬膜内に位置する paraclinoid intradural aneurysm, dural ringより近位側の硬膜外に位置する infraclinoid extradural aneurysm, carotid caveに位置する carotid cave aneurysm とに分類した ${ }^{10)}$ (Fig. 3).さらに, 術野における内頸動脈の横断面での動脈瘤ネックの位置に より, 外側, 内側, 腹側, 背側の各型に分類した ${ }^{13}$ (Fig. 4).

\section{Paraclinoid intradural aneurysm(傍前床突起硬膜内動} 脈瘤)(Fig. 5)

dural ringに近接する硬膜内に発生する動脈瘤で，内頸 動脈眼動脈分岐部動脈瘤および, ophthalmic segment ${ }^{2)}$ (後交通動脈動脈分岐部から眼動脈分岐部まで)より発生す る動脈瘤(眼動脈瘤)の中で, 特にdural ringに近接する動 脈瘤を含む。側面血管写では，多くの場合眼動脈分岐部よ り遠位側に位置する(Fig. 7).

\section{Carotid cave aneurysm (内頸動脈窩動脈瘤)(Fig. 6)} carotid caveに発育する動脈瘤で, 動脈瘤ネックは, 多 くの場合眼動脈より近位側に位置する (Fig. 7). carotid 

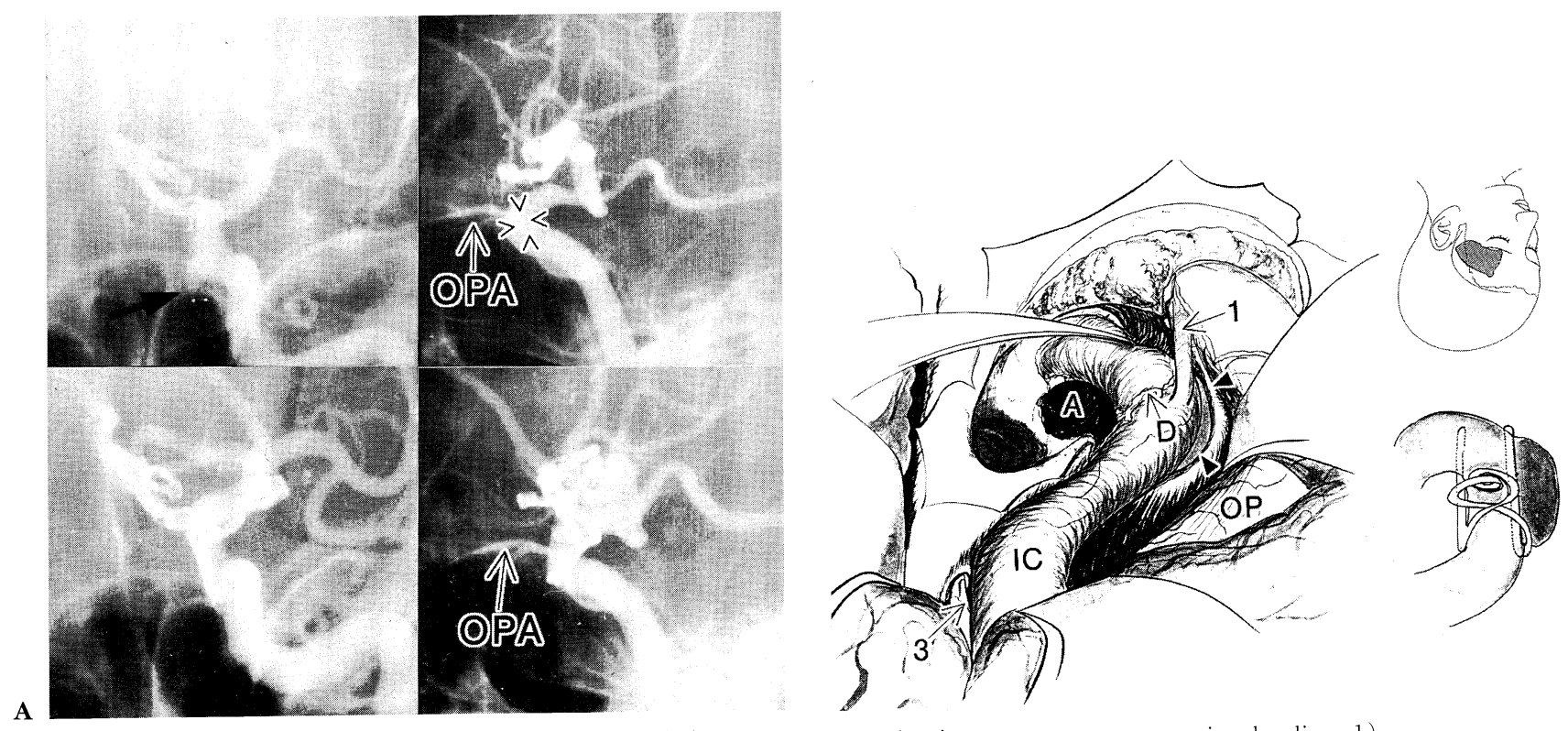

B

Fig. 6 Carotid cave aneurysm (left). (Anterior communicating aneurysm was previously clipped.) A: Upper: Preoperative angiograms. Note that the aneurysm is located medially on the A$\mathrm{P}$ view, and is located at the angiographical genu proximally to the ophthalmic artery on the lateral view. Lower: Postoperative angiograms. Arrow and arrowheads indicate the aneurysm. OPA: ophthalmic artery.

B: Operative drawing. Note that the aneurysm is situated ventrally in the operative field locating in the carotid cave. Arrowheads indicate the aneurysm. Abbreviations as in Fig.

2. (文献 12 より引用)

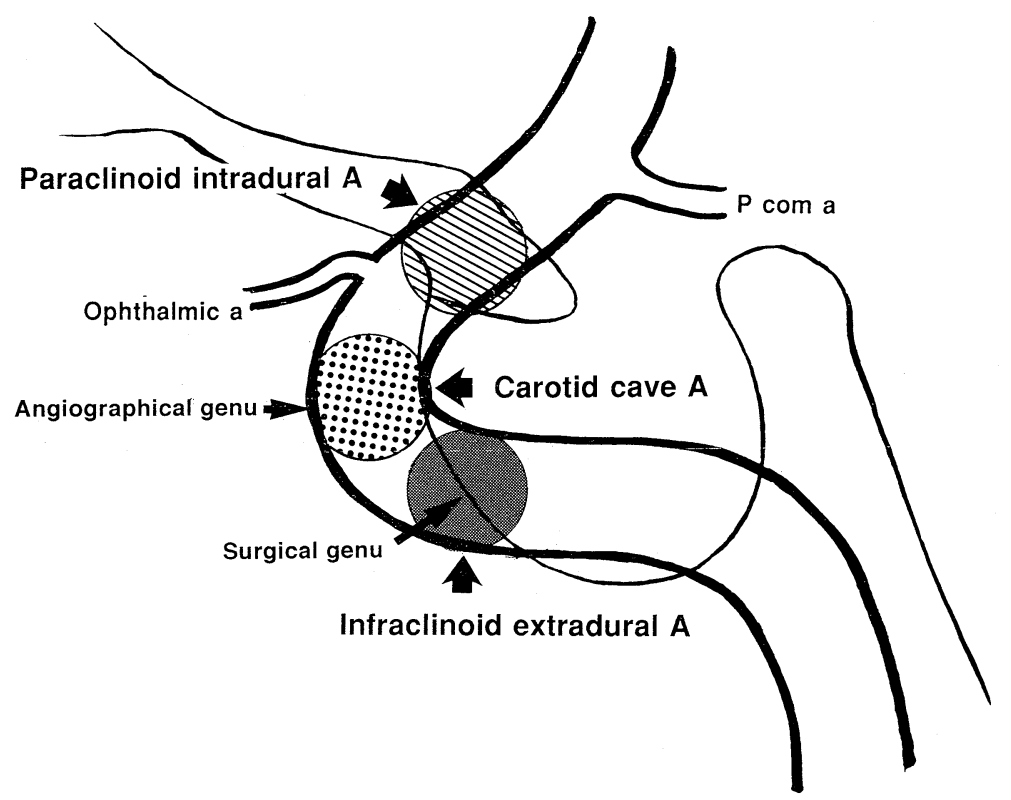

Fig. 7 Schematic drawing of locations of juxta-dural ring aneurysms on the lateral angiogram.

Note that the carotid cave aneurysms are located at the angiographical genu (the anterior siphon knee) and proximally to the origin of the ophthalmic artery, the paraclinoid intradural aneurysm distally to the ophthalmic artery, and the infraclinoid extradural aneurysm just proximally to the angiographical genu, where is correspond to the surgical genu. P com a: posterior communicating artery. (文献10,11より一部改変) 
caveの解剖学的位置関係から, 術野での動脈瘤の位置は 腹側であり，血管写では，側面像では angiographycal genu部で内頸動脈と重なるように，また正面像で内側に 向いているのが特徴である。内側に向いていない場合は carotid cave aneurysmではなくinfraclinoid extradural aneurysmである ${ }^{11)}$.

\section{Infraclinoid extradural aneurysm (前床突起下硬膜外動 脈瘤)(Fig. 5)}

infraclinoid sinus内の infraclinoid segmentに発生する 硬膜外動脈瘤で, 硬膜外より dural ringに近接するもので ある。血管写側面像では最大弯曲部よりわずかに近位側に 認められる(Fig. 7). 解剖学的にも手術手技的にも海綿静脈 洞部動脈瘤とは厳密に区別すべきものである.

我々がこれまで経験した硬膜輪近傍動脈瘤は72例であ る(Table 1). paraclinoid intradural aneurysmは33例で, 外側, 内側，腹側，背側いずれの方向にもみられた。 carotid cave aneurysmは34例で，すべて腹側である。 infraclinoid extradural aneurysmは 4 例で，腹側，外側に みられた。他に前床突起直下の硬膜輪部に発生した分類困 難ものが 1 例認められた。動脈瘤破裂によるクモ膜下出血 は paraclinoid intradural aneurysm 6 例, carotid cave aneurysm 3 例の計 9 例にみられた.クリッピングは前床 突起直下の硬膜輪部に認められた 1 例を除き全例に行っ た。手術成績はfair 1 例, poor 1 例, 視野障害を生じたも の8例であった。

\section{血管写側面像における動脈瘤の位置}

Fig. 7 は，術後の血管写側面像のクリップの位置の検討 から, 硬膜輪近傍動脈瘤の長軸方向での各動脈瘤ネックの 位置を示した模式図である。眼動脈の分岐部, angiographical genuの形状には個人差もみられるが, 眼動脈の 分岐部および angiographical genuが各動脈瘤の長軸方向 での位置を知る指標となる。

\section{手術手技 ${ }^{11)}$}

硬膜輪近傍動脈瘤の手術では基本的に共通した手術手技 が必要とされ, すべて pterional approachで手術可能であ る.この部では視神経と内頸動脈が上下に位置するように なることから, 通常の内頸動脈瘤手術の場合よりさらに頭 部を対側に回転させる必要がある。我々は約 45 度頭部を 対側に回転させている。

動脈瘤手術の基本は動脈瘤ネックの近位側および遠位側 を露出確保するとともに, 動脈瘤ネックの周囲を十分に露 出することにある，そのためには，前床突起の切除により infraclinoid grooveを十分に開放し，さらにinfraclinoid
Table 1 Profile of juxta-dural ring aneurysms

\begin{tabular}{lccccc}
\hline & lat & med & ven & dor & Total \\
\hline Paraclinoid intradural & $3(1)$ & 6 & $18(4)$ & $6(1)$ & $33(6)$ \\
Carotid cave & & & $34(3)$ & & $34(3)$ \\
Infraclinoid extradural & 2 & & 2 & & 4 \\
Others & & & & & 1 \\
\hline & $5(1)$ & 6 & $54(7)$ & $6(1)$ & $72(9)$ \\
\hline ( )=large to giant aneurysms & & & &
\end{tabular}

sinusを開きinfraclinoid segmentを露出させ， dural ring を内頸動脈の全周にわたり切離することが重要である。ま た, 特に腹側型の動脈瘤のクリッピングに際して, axilla を露出確保し，リングクリップのブレイドがこの部にはい ることを確認することが内頸動脈を閉塞させないために大 切である. dural ringの切離は, クリップのブレードを動 脈瘤ネックを越えて送り込むために，またdural ring部で 内頸動脈の狭宱を起こさないためにも必要な手術手技であ る、視神経管の開放, 眼動脈を視神経管内硬膜より剥離す ることは動脈瘤ネックの露出やクリッピングに際して視神 経および内頸動脈の圧排を安全に行うために必須である。

\section{考察}

我々は長軸方向での動脈瘤の位置で分類し，これをさら に内頸動脈の横断面での位置による分類を加えた。長軸方 向での動脈瘤の位置に関しては，dural ringに注目し，分 岐動脈に関係なくdural ringより遠位側(硬膜内) 加近位側 (硬膜外)かに分類した.

以前の報告 ${ }^{11)}$ では，硬膜輪近傍動脈瘤をintradural aneurysm, carotid cave aneurysm, infraclinoid aneurysm とに分類することを提唱したが，内頸動脈は海綿静脈洞か ら前床突起基部の infraclinoid sinus を経て固有硬膜を貫通 し, 硬膜内に至ることから用語上の混乱を解消すべく, intradural aneurysm paraclinoid intradural aneurysm にまたinfraclinoid aneurysmを infraclinoid extradural aneurysmに改名した. paraclinoid intradural aneurysm と carotid cave aneurysmは破裂によりクモ膜下出血を生じ る.

\section{1. 各動脈瘤について}

1) Paraclinoid intradural aneurysm: Yaşargil ${ }^{20)}$, Fox ${ }^{5)}$, Nutik $^{14)}$, Day ${ }^{2)}$ らいう ventral internal carotid aneurysm, paraclinoid aneurysm, superior hypophyseal artery aneurysmはほぼこれに相当するが，彼らの症例の中には 我々のいう carotid cave aneurysmが一部含まれている。

2) Carotid cave aneurysm: paraclinoid intradural 
aneurysm と infraclinoid extradural aneurysmの移行部に 発生するものといえるが, 解剖学的には硬膜内(クモ膜下 腔内) である。従来は多くの場合, 海綿静脈洞部動脈瘤と されていたものであり, 手術に際しては, 前床突起切除の みでは通常の硬膜内には動脈瘤の全貌は観察されず，手術 不可能とされていたものである.

Day $^{2)}$, Rhoton ${ }^{17)}$, 佐野 ${ }^{18)}$ らは clinoid space と carotid caveは同じとしているが，上述のごとく，解剖学的にclinoid space (infraclinoid space) と carotid caveは明らかに異 なるものである。 clinoid spaceは extradural spaceであり， carotid caveは intradural spaceである.

3) Infraclinoid extradural aneurysm: 従来の海綿静脈 洞部動脈瘤に含まれるが, 前床突起を切除しinfraclinoid sinusを解放して初めて確認される. Perneczky ${ }^{15116)}$ の いう infraclinoid(al) anuerysm, Al-Rodhan $ら^{1)} の$ transitional cavernous aneurysm はほぼこれに相当するが, 彼 らの症例の中にはcarotid cave aneurysmが一部含まれて いる.

硬膜輪近傍動脈㾿における, 手術所見と血管写所見を比 較してみると, surgical genuと angiographical genu (FischerのC ( 部 $\left.^{4}\right)$ との間には位置のずれが認められ， surgical genuは angiographical genuよりやや近位側に位 置する(Fig. 7)。これは術野の方向と血管写の方向とのず れによるものと考えられる。

\section{2.内頸動脈の横断面での動脈瘤の位置に対する名称につ いて}

我々の分類は, pterional approachによる術野での術者 からみた主観的分類である. pterional appraochにおいて 内頸動脈を観察すると, 通常は内頸動脈は術野で水平にみ える。この場合, 術野で術者からみて内頸動脈の手前, す なわち術者の進入路に向かって飛び出すように発育した動 脈瘤を何とよぶのが適当かということが問題となる。この 動脈瘤は, 患者の頭を対側に回転させた pterional approachでの術野であるということを念頭に置くと, 解 剖学的(放射線学的)には anterolateralあるいは superiolateral wallに位置する動脈瘤である。硬膜内の内頸動脈は側 面血管写像では斜めに走行しているので解剖学的には anterior はsuperior とも解釈される。よって, 解剖学的に は anterior wall aneurysmというょりは, anterolateral (superiolateral) wall aneurysmとするのがより正確である. しかし, これは術野での分類としては煩雑である。術野か ら浮かぶイメージ，クリッピングなどの手術手技と直結す る名称が好ましい.

我々は, 解剖学的用語ではなく, 術野用語あるいは通称 として, 術野で術者からみて内頸動脈の手前に位置する場 合，背側(dorsal)に位置するとした。術野で動脈の背側に 位置する動脈瘤(dorsal aneurysm) は，あくまでも内頸動 脈の横断面での位置からみた名称であり, 動脈溜の形状か らみたよび名であるblister aneurysm ${ }^{19)}$ ，あるいは病理学 的分類であるdissecting aneurysmとは分類上は根本的に 異なるものである.

いずれにしろ，我々の提唱したdorsal aneurysmを anterior wall aneurysm (前壁動脈瘤) ${ }^{18)}$ とよぶことは新たな混乱 を避けられない。なぜなら，もし anterior wallの意味を解 剖学的意味で使用するのなら，この動脈瘤は術野では内頸 動脈の内側よりに位置することになり，我々のいうdorsal aneurysmとは異なることになる。また anterior wall aneurysmという意味を, 術野で手前に飛び出した動脈瘤 とすると, anterior という意味が本来の解剖学的意味をな さなくなるという矛盾があるからである. Yaşargil ${ }^{21)} も$ superiorを解剖学的な意味ではなく術野用語として使用し て抢り, pterional approachにおける術野で手前に飛び出 ているものを superior wall aneurysmとしているが, anterior, superiorなど解剖学的に確立された用語を術野用語と して使用することは混乱をまねく。また確かな解剖学的用 語を術野用語として使用することは誤解を生ずる恐れがあ ると考え, 解剖学的用語としては曖昧な dorsalを術野用語 として使用した。

\section{文献}

1) Al-Rodhan NRF, Piepgras DG, Sundt TM Jr: Transitional cavernous aneurysms of the internal carotid artery. Neurosurgery 33: 993-998, 1993

2) Day AL: Aneurysms of the ophthalmic segment. A clinical and anatomical analysis. J Neurosurg 72: 677-691, 1990

3) Dolenc VV: Anatomy and Surgery of the Cavernous Sinus. Springer-Verlarg, Wien/New York, 1989, pp 3-25

4) Fischer E: Die Lageabweichungen der vorderen Hirnarterie im Gefassbild. Zbl Neurochir 3: 300-312, 1938

5) Fox JL: Microsurgical treatment of ventral (paraclinoid) internal carotid aneurysms. Neurosurgery 22: 32-39, 1988

6) Gibo H, Lenkey C, Rhoton AL Jr: Microsurgical anatomy of the supraclinoid portion of the internal carotid artery. J Neurosurg 55: 560-574, 1981

7) Kobayashi S, Kyoshima K, Gibo H, et al: Carotid cave aneurysms of the internal carotid artery. J Neurosurg 70: 216-221, 1989

8) Kobayashi S, Koike G, Orz Y, et al: Juxta-dural ring aneurysms of the internal arotid artery. J Clin Neuroscience 2: 345-349, 1995

9) Kyoshima K, Kobayashi S: Carotid cave aneurysms of the internal carotid artery. Intracranial Aneurysms and Arteriovenous Malformations. Nagoya University COOP Press, Nagoya, 1990, pp 197-207

10) Kyoshima K, Koike G, Hokama M, et al: A classification of juxta-dural ring aneurysms with reference to surgical anatomy. J Clin Neuroscience 2: 61-64, 1996

11）京島和彦, 小林茂昭, 宜保浩彦, ほか：内頸動脈硬膜輪近 
傍動脈瘤の手術手技と外科一解剖について. 脳卒中の外科 19: 165-172, 1991

12）京島和彦, 外間政信, 宜保浩彦, ほか: 内頸動脈硬膜輪近 傍の外科解剖。顕微鏡下手術のための脳神経外科解剖 V. 第 6 回微小脳神経外科解剖セミナー(1992)講演集, pp 130136

13）京島和彦：II. Standard Techniques 3. 内頸動脈 手術手技, 山浦 晶(編) 脳動脈瘤の外科, 医学書院, 1995, pp 84-98

14) Nutik SL: Ventral paraclinoid carotid aneurysms. J Neurosurg 69: 340-344, 1988

15) Perneczky A, Knosp E, Vorkapic P, et al: Direct surgical approach to infraclinoidal aneurysms. Acta Neurochir $\mathbf{7 6}$ : 36-44, 1985

16) Perneczky A, Knosp E, Czech TH: Para- and infraclinoid aneurysms: Anatomy, surgical technique, and report of 22 cases. In: Dolenc VV (ed), The Cavernous Sinus, Springer, Berlin, 1987, pp 252-271

17) Rhoton AL Jr: Anatomic foundations of aneurysm surgery (Honored Guest Lecture). Clin Neurosurg 41: 289-324, 1994

18）佐野圭司：内頸動脈のいわゆる dorsal aneurysm, carotid cave aneurysm等の名称と分類に関する考察. 脳卒中の外科 24: 333-339, 1996

19）高橋 明, 鈴木二郎, 藤原 悟, ほか : 内頸動脈 $\mathrm{C} 2$ 部チマ 又状動脈瘤の手術。脳卒中の外科 16: 72-77, 1988

20) Yaşargil MG, Fox JL: The microsurgical approach to intracranial aneurysms. Surg Neurol 3: 7-14, 1975

21) Yaşargil MG: Internal carotid artery aneurysms. In: Microneurosurgery II, Georg Thieme Verlag, Stuttgart New York, 1984, pp 33-123 